\title{
Characterization of galactomannans extracted from seeds of Gleditsia triacanthos and Sophora japonica through shear and extensional rheology: Comparison with guar gum and locust bean gum
}

\author{
Bourbon A.I. ${ }^{a}$, Pinheiro A.C. ${ }^{a}$, Ribeiro C. ${ }^{\mathrm{a}, \mathrm{b}}$, Miranda C. ${ }^{\mathrm{b}}$, Maia J.M., ${ }^{\mathrm{c},}$, Teixeira J.A. ${ }^{\text {, }}$ Vicente A.A. ${ }^{\mathrm{a} *}$ \\ ${ }^{a}$ IBB - Institute for Biotechnology and Bioengineering, Centre of Biological Engineering, University of Minho, Campus de Gualtar, 4710-057 Braga, Portugal \\ ${ }^{\mathrm{b}}$ Research and Development Department, Frulact, S.A., Rua do Outeiro, 589, Gemunde, 4475-150 Maia, Portugal \\ ${ }^{c}$ IPC-Institute for Polymers and Composites, University of Minho, Campus de Azurém, 4800-058 Guimarães, Portugal \\ ${ }^{\mathrm{d}}$ Case Western Reserve University, Department of Macromolecular Science and Engineering, 2100 Adelbert Rd., Cleveland, OH 44106, United States
}

\section{A R T I C L E I N F O}

\section{Article history:}

Received 4 May 2009

Accepted 1 September 2009

\section{Keywords:}

Non-traditional galactomannans

Shear rheology

Extensional rheology

\begin{abstract}
A B S T R A C T
The rheological behaviour, under steady and dynamic shear and extensional conditions, of two nonconventional galactomannans isolated from Gleditsia triacanthos and Sophora japonica is determined and compared to those of locust bean gum and guar gum.

The studied galactomannans exhibit shear-thinning behaviour in the range of concentrations and shear rates evaluated. For similar concentrations and shear rates, the guar gum exhibits the highest viscosities. Experimental data in steady shear was correlated with the Cross model, which provided a good description of viscosity shear rate data. Under oscillatory shear, all gum solutions exhibited a behaviour typical of random-coil polysaccharide solutions.

The extensional rheology experiments showed that by increasing the polymer concentration and decreasing the temperature, the relaxation times, elastic moduli and rupture times increase.

These findings lead to the conclusion that $G$. triacanthos and S. japonica galactomannans can be used as efficient thickening hydrocolloids as alternative to conventional galactomannans.
\end{abstract}

(c) 2009 Elsevier Ltd. All rights reserved.

\section{Introduction}

Galactomannans, storage polysaccharides isolated from the seed endosperm of some Leguminosae, are composed of a linear mannan main chain with side chains of a single galactose (Dea \& Morrison, 1975).

The two galactomannans of major commercial importance are Guar Gum (GG) from Cyamopsis tetragonolobus and Locust Bean Gum (LBG), from Ceratonia siliqua, which have mannose/galactose ratios $(M / G)$ of 1.8:1 and 3.5:1 (Dakia, Blecker, Roberta, Watheleta, \& Paquota, 2008) and molecular weight in the range of $0.697 \times 10^{6}$ $0.94010^{6}$ Da (Parvathy, Nuggehalli, \& Tharanathana, 2007) and $0.856 \times 10^{6}-1.20 \times 10^{6}$ Da (Dakia et al., 2008), respectively. They are extensively applied in the food industry as thickening and stabilizing agents, due to their low cost and wide range of functional properties (Cheng, Brown, \& Prud'homme, 2002).

Galactomannans have the ability to form very viscous solutions at low concentrations, which are lightly affected by $\mathrm{pH}$, addition of

\footnotetext{
* Corresponding author. Tel.: +351 253 604419; fax: +351 253678986.

E-mail address: avicente@deb.uminho.pt (A.A. Vicente).
}

electrolytes and heat processing (Sittikijyothin, Torres, \& Gonçalves, 2005). These solutions usually exhibit a non-Newtonian behaviour, in which the viscosity decreases with the increase of shear rate (Garti, Madar, Aserin, \& Sternheim, 1997). The Cross (1965) model has been successfully used to describe the shear-thinning behaviour of most galactomannans (da Silva, Gonçalves, \& Rao, 1992; Sittikijyothin et al., 2005). When associated with other polysaccharides, such as xanthan gum and kappa-carrageenan, galactomannans can form gels with new properties (Andrade, Azero, Luciano, \& Gonçalves, 2000; Azero \& Andrade, 2006; Bresolin, Milas, Rinaudo, Reicher, \& Ganter, 1999; Casas, Mohedano, \& Garcia-Ochoa, 2000; Fernandes, Gonçalves, \& Doublier, 1991 and Hernandez, Dolz, Dolz, Delegido, \& Pellicer, 2001).

Their functional properties are connected to their molar mass and structural features: the solutions' viscosity depends mainly on the molar mass while the synergistic interactions seem to be determined by the mannose/galactose ratio (M/G) and fine structure of galactomannan chain (Dea, Clark, \& McCleary, 1986; Fernandes et al., 1991; Schorsch, Gamier, \& Doublier, 1997).

Since the hydrocolloids are used to modify textural attributes, the study of their rheological behaviour is essential as it is recognized that rheological properties play an important role in process 
design, evaluation and modelling. Furthermore, rheological data is required for calculation in any process involving fluid flow (e.g. pump sizing, extraction, filtration, extrusion, purification) and play an important role in the analyses of flow conditions in food processes such as pasteurization, evaporation, drying and aseptic processing (Marcotte, Taherian, Trigui, \& Ramaswamy, 2001).

While considerable work has been published on the rheological characterization of LBG and GG under shear flow (Choi \& Yoo, 2008; Doublier \& Launay, 1981; Patel, Ranjan, \& Patel, 1987; Sittikijyothin et al., 2005), the work done with non-traditional sources of galactomannans is scarce.

Mazzini and Cerezo (1979) first reported the presence of galactomannans in the seeds of Gleditsia triacanthos (a Leguminosae). This species can tolerate a wide range of climatic and soil conditions (Blair, 1990) and is spread in America, Middle Europe and Mediterranean countries (Üner \& Altınkurt, 2004). Its seeds are composed of testa (27\%), embryo (29\%) and endosperm (34\%) and galactomannans are the main polysaccharide constituents of the endosperm (Manzi, Mazzini, \& Cerezo, 1984). The galactomannan of G. triacanthos used in this study was previously characterized in terms of $\mathrm{M} / \mathrm{G}$ ratio, intrinsic viscosity and viscosity average molar mass and the obtained values were 2.82:1, $1042 \mathrm{ml} / \mathrm{g}$ and $1.62 \times 10^{6} \mathrm{Da}$, respectively (Cerqueira et al., 2009). Sophora japonica (also a Leguminosae) is native from China, where it is widely cultivated and used as a hemostatic agent in traditional medicine and is currently spread all over the word (Ishida, Umino, Tsuji, \& Kosuge, 1989; Tang, Lou, Wang, \& Zhuang, 2001). The galactomannan extracted from $S$. japonica used in this study has been previously characterized and exhibits an unusually high $\mathrm{M} / \mathrm{G}$ ratio (5.75:1), an intrinsic viscosity of $1001 \mathrm{ml} / \mathrm{g}$ and a viscosity average molar mass of $1.34 \times 10^{6} \mathrm{Da}$ (Cerqueira et al., 2009).

Extensional rheology can be used to complement data obtained from conventional shear rheometers and to fully characterize fluid properties (Odell \& Carrington, 2006). It is much less studied, partly due to difficulties in creating a pure extensional flow. However, the extensional component is an important part of many food-processing operations, and it may be also very useful for consumer perception studies and quality evaluation of food products. Operations such as mixing, homogenization, sheeting, extrusion, extrudate expansion, baking expansion, flow in and out of constrictions and coating are all examples of processes with significant extensional component. From the consumer's standpoint, spreadability, pourability, mouthfeel, stinginess and stretchability are important attributes where extensional rheology dominates the textural perception (Padmanabham, 2003). An extensional deformation differs significantly from a shear deformation. During a shear deformation, the particles within the flowing body move in the same direction and slide over each other, while during an extensional deformation, as the material is either stretched or compressed, the particles within the fluid will either move away or towards each other (Chan et al., 2007). Contrary to shear rheology, in extensional measurements the cross-sectional area of the sample undergoes a modification as a consequence of the exponentional change in length. Therefore, the extensional rheology allows the evaluation of interfacial multicomponent phenomena (Steffe, 1996).

The extensional properties of a fluid can be quantified by various means, including a Capillary Break-up Elongation Rheometer (CaBER), as in the present work. The rheological analysis with a CaBER is based on the formation of an unstable fluid filament by imposing a rapid axial step-strain of prescribed magnitude. The filament is then allowed to relax until breakup under the action of its own dynamics. The relaxation and decay of the necked sample is governed by different forces, e.g. viscous, elastic, gravitational and capillary forces (Sujatha, Matallah, Banaai, \& Webster, 2008). This technique allows the creation of a pure extensional flow and can be applicable to fluids over a wide range of viscosities.

Little is known about the extensional behaviour of galactomannans. In the present work, two non-conventional galactomannans were isolated from G. triacanthos and S. japonica seeds, and their rheological behaviour, in steady and dynamic shear and in extensional conditions was determined and compared with those of guar gum and locust bean gum, in order to investigate their effectiveness as alternative thickening hydrocolloids. The flow curves of each gum have been correlated with the Cross model.

The results of this study will contribute to the research of novel renewable sources of hydrocolloids, as alternatives to the traditional ones, and to the development of novel foods, addressing the claims of the modern consumer.

\section{Materials and methods}

\subsection{Materials}

The pods of $G$. triacanthos ( $\mathrm{M} / \mathrm{G}=2.81: 1$, Cerqueira et al., 2009) and S. japonica (M/G = 5.75:1, Cerqueira et al., 2009) were collected in the Botanic Garden in Porto, Portugal, during April 2006 and February 2008, respectively. The seeds were manually separated and kept in a cool, dry place until further commercial use. Commercial Guar Gum (GG) (Viscogum, Cargill) (M/G = 1.8:1, Dakia et al., 2008) and commercial Locust Bean Gum (LBG) (Genu gum type RL-200V, $\mathrm{CP}$ Kelco $)(\mathrm{M} / \mathrm{G}=3.5: 1$, Dakia et al., 2008) were used as control.

\subsection{Methods}

\subsubsection{Polysaccharide extraction and purification}

The extraction of polysaccharide from $G$. triacanthos and S. japonica was performed according to Cerqueira et al. (2009). Briefly, the extraction of galactomannans from $G$. triacanthos was performed with ethanol and distilled water. In this process, the seeds were mechanically broken, the endosperm was separated from the germ and the hull and was suspended in ethanol (purity $99.8 \%$, Riedel-de Haën, Germany) to inactivate the enzymes and to eliminate low-molecular-weight compounds (Egorov, Mestechkina, \& Shcherbukhin, 2003; Egorov, Mestechkina, \& Shcherbukhin, 2004). Following this step, distilled water was added and the suspension was mixed in a blender.

The extraction procedure of galactomannan from the seeds of $S$. japonica required an acidic pretreatment in order to effectively separate the hull from the endosperm. The seeds were peeled using sulfuric acid (purity $98 \%$, Fluka, Germany) (1:1) in a water bath at $100^{\circ} \mathrm{C}$ for $1.5 \mathrm{~h}$. After the endosperm removal and after its treatment with ethanol, water was added to it and the mixture was heated at $80^{\circ} \mathrm{C}$.

The purification process of both galactomannans included a filtration through a nylon net followed by a centrifugation step at $3800 \mathrm{~g}$ (Sigma $4 \mathrm{~K}$, B.Braun, Germany) during $20 \mathrm{~min}$ at $20^{\circ} \mathrm{C}$. The precipitation of galactomannan was achieved by adding the supernatant to ethanol (purity 99.8\%, Riedel-de Haën, Germany) at a ratio of $1: 2$. The precipitated galactomannan was lyophilized and kept in a dry place until further use (Cerqueira et al., 2009).

\subsubsection{Solution preparation}

The required quantity of powdered gums was added to the appropriate amount of distilled water in the presence of sodium azide $(5 \mathrm{ppm})$ in order to prevent bacterial degradation. The dispersions of the four gums were stirred at room temperature overnight; the dispersions of locust bean gum, S. japonica and G. triacanthos gums were also subjected to a further stirring period $(1 \mathrm{~h})$ at a higher temperature $\left(80{ }^{\circ} \mathrm{C}\right)$ in order to ensure their complete solubilization. 
The solutions were centrifuged for $1 \mathrm{~h}$ at $20,000 \mathrm{rpm}$ and the supernatants were recovered. The final polymer concentrations were determined as total solids dried at $105{ }^{\circ} \mathrm{C}$ until constant weight.

\subsubsection{Chemical analyses}

Moisture content was determined according to AOAC standards (1975), protein content was assessed using Bradford's method (Bradford, 1976) and ash content was evaluated by heating the sample in a muffle furnace at $500{ }^{\circ} \mathrm{C}$ for $8 \mathrm{~h}$ followed by cooling and weighing (Ranganna, 1977).

\subsubsection{Rheological properties}

2.2.4.1. Shear rheological tests. All rheological shear measurements were carried out at $25^{\circ} \mathrm{C}$, with a TA Instruments AR-G2 controlledstress rheometer, using parallel plates $(25 \mathrm{~mm}$ diameter and $1 \mathrm{~mm}$ gap). Steady-state flow curves were obtained working in controlled-stress mode, over the shear rate range of $0.01-1000 \mathrm{~s}^{-1}$.

Frequency sweeps were performed in the $0.1-100 \mathrm{rad} \mathrm{s}^{-1}$ range and the strain was fixed at $5 \%$ in order to assure that the working conditions lied in the linear viscoelastic region. In fact, before performing frequency spectra, the linear viscoelastic region was determined and the appropriate strain was selected, by means of strain sweeps conducted at a constant frequency $\left(6.279 \mathrm{rad} \mathrm{s}^{-1}\right.$ ) and variable strain ranging from 0.01 to $10 \%$. This type of test determines the maximum deformation attainable for a system without structural failure.

For each sample and due to the non-destructive character of oscillation measurements of low frequency, the mechanical spectra preceded the flow curves. All the measurements were performed in triplicate.

\subsubsection{Extensional rheological tests}

Extensional rheology tests were carried out using a Haake CaBER-1 extensional rheometer (Thermo Haake GmbH, Karlsruhe, Germany), equipped with two $6 \mathrm{~mm}$ circular parallel plates. In order to minimize the influence of gravity and shear flow during the early stages of stretch, plates were set at an initial gap of $2 \mathrm{~mm}$, resulting in an aspect ratio (initial length to radius, $L / R$ ) equal to 0.33 . Fluid samples were carefully loaded between the plates using a syringe to ensure the absence of trapped air within the sample cylinder, or between the sample and the plates. The upper plate was suddenly raised to a pre-set height of $6 \mathrm{~mm}$ to create a filament and a laser beam aiming at the middle point of the filament monitored the changes in diameter. All extensional tests were repeated at least six times and their average was taken for analysis.

The sample temperature $\left(25,40,50,60\right.$ and $\left.80{ }^{\circ} \mathrm{C}\right)$ was controlled by a water bath circulating underneath the plates with an accuracy of $0.1{ }^{\circ} \mathrm{C}$. Prior to testing, samples were thermally equilibrated in a water bath to testing temperature.

The surface tensions of fluid samples, required for the relaxation time calculation, were determined using a Surface Tensiometer K6 (KRUSS Gmbh, Germany), using a Platinum-Iridium Du Nouy ring, at the testing temperature. All the measurements were performed in triplicate. For decreasing concentrations, the surface tension is in the range of $0.068-0.073 \mathrm{~N} / \mathrm{m}$ for locust bean gum, $0.056-0.064 \mathrm{~N} / \mathrm{m}$ for guar gum, $0.044-0.050 \mathrm{~N} / \mathrm{m}$ for $G$. triacanthos galactomannan and $0.038-0.043 \mathrm{~N} / \mathrm{m}$ for $S$. japonica galactomannans.

\section{Results and discussion}

\subsection{Chemical analyses}

The composition of the gums is given in Table 1. The purification process was sufficient to eliminate ash and proteins in G. triacanthos
Table 1

Moisture, ash and protein of Locust Bean Gum (LBG), Guar Gum (GG), G. triacanthos galactomannan and S. japonica galactomannan ( $\pm 95 \%$ confidence interval).

\begin{tabular}{llll}
\hline Galactomannans & \%Moisture & \%Ash & \% Protein \\
\hline LBG & $11.38 \pm 0.01$ & $0.16 \pm 0.01$ & $0.01 \pm 0.007$ \\
GG & $11.70 \pm 0.03$ & $0.72 \pm 0.01$ & $0.05 \pm 0.030$ \\
G. triacanthos & $10.17 \pm 0.01$ & $0.08 \pm 0.01$ & $0.07 \pm 0.023$ \\
S. japonica & $13.39 \pm 0.02$ & $0.32 \pm 0.02$ & $0.06 \pm 0.015$ \\
\hline
\end{tabular}

and S. japonica galactomannans, thus providing final products with a quality comparable to commercial gums (locust bean gum and guar gum).

\subsection{Steady-shear properties}

The effect of shear rate on viscosity, at $25{ }^{\circ} \mathrm{C}$, for locust bean, guar, G. triacanthos and S. japonica gum solutions of different concentrations is shown in Fig. 1. The values of viscosity at low shear rates are an indication of the consistency in mouth of the product (Morris \& Taylor, 1982), while the values of viscosity at high shear rates are an indication of the viscosity of the product during processing operations (e.g. when it is pumped) (Dakia et al., 2008). In all cases, a shear-thinning behaviour was observed that may be regarded as arising from modifications in the macromolecular organization of the solution as the shear rate changes. With increasing shear rate, the disruption predominates over formation of new entanglements, molecules align in the direction of flow and the viscosity decreases (Dakia et al., 2008; Sittikijyothin et al., 2005).

For similar concentrations and shear rates, the guar gum exhibits the highest viscosities. The flow curves obtained for guar and locust bean gums are in good agreement with the results reported in the literature (Andrade, Azero, Luciano, \& Gonçalves, 1999; Sittikijyothin et al., 2005; Wientjes, Duits, Jongschaap, \& Mellema, 2000).

Experimental data in steady shear was modelled with the Cross (1965) model (Eq. (1)):

$\eta=\eta_{\infty}+\frac{\left(\eta_{0}-\eta_{\infty}\right)}{\left[1+(\tau \gamma)^{m}\right]}$

where $\dot{\gamma}$ is the shear rate $\left(\mathrm{s}^{-1}\right), \eta$ is the viscosity (Pa.s), $\eta_{0}$ is the zero-shear rate viscosity (Pa.s), $\eta_{\infty}$ is the infinite shear rate viscosity (Pa.s), $\tau$ (s) is a time constant, and $m$ is a dimensionless constant. Since the high shear rate Newtonian viscosity was never approached in this study, the above equations were simplified, assuming $\eta_{0}>>\eta_{\infty}$ (Eq. (2)).

$\eta=\frac{\eta_{0}}{\left[1+(\tau \gamma)^{m}\right]}$

From Fig. 1 and Table 2 it can be seen that the experimental data of all the studied galactomannans were adequately described by this model, as indicated by the magnitudes of the regression coefficient, $R^{2}$.

In all cases, due to the increase of the shear-thinning behaviour with concentration, the values of $c_{0}$ and $\tau$ increase with increasing concentration. The magnitude of zero-shear rate viscosity is a macroscopic representation of the microstructural nature of biopolymers; a higher value of $c_{0}$ indicates the establishment of a greater number of links between the biopolymer molecules and depends on the molar mass and on interchain interactions (junctions zone). The parameter $\tau$ corresponds to the structural relaxation time and its increase with concentration is due to an increase of the chains' entanglement density. As a result, the freedom of 

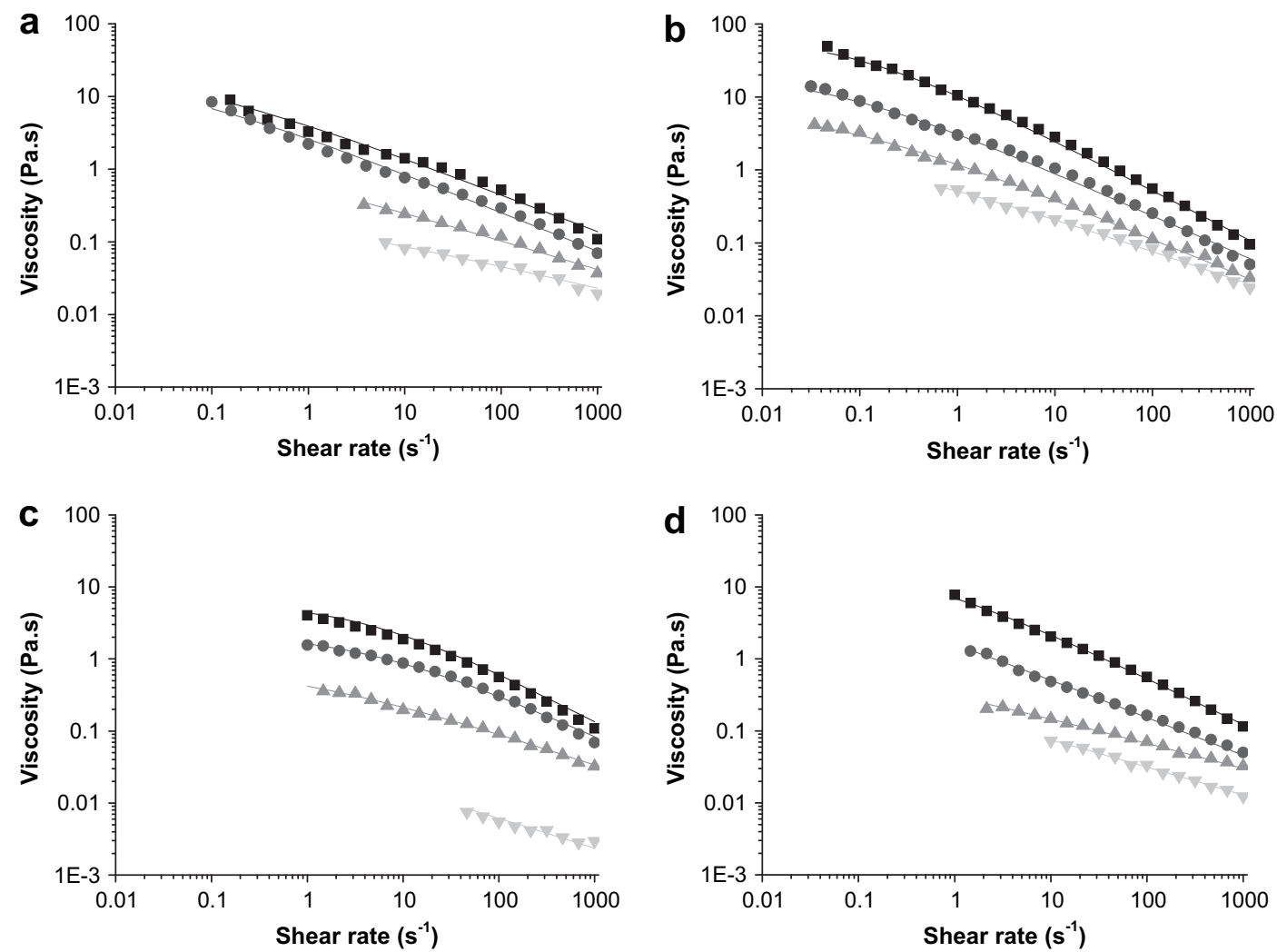

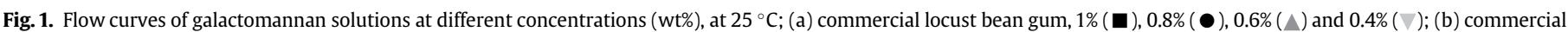

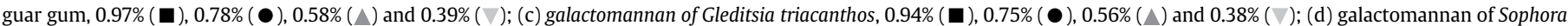
japonica, 0.96\% ( $\mathbf{\square}), 0.77 \%(\bullet), 0.58 \%(\Delta)$ and $0.38 \%(\nabla)$; The full line represents the best fits of the cross model.

movement of individual chains is progressively restricted and consequently increases the time needed to form new entanglements to replace those destroyed by the external deformation. Therefore, the shear rates values for which the behaviour becomes shear-thinning decrease as the concentration increases. Values of the dimensionless exponent $m$ tending to zero, describes an increasing Newtonian behaviour, while fluids with shear-thinning behaviour exhibit $m$ tending to 1 . The parameter $m$ obtained for the studied galactomannans assumes values between 0.5 and 0.6 , which are the typically expected values for polymer solutions.

\subsection{Dynamic shear properties}

The frequency sweeps for all galactomannan solutions are shown in Fig. 2. At low frequencies, the viscous modulus $G^{\prime \prime}$, related to the viscous response of the system, is higher than the elastic modulus $G^{\prime}$, i.e. the system shows a liquid-like behaviour until a crossover frequency after which it is reversed and the elastic response prevails. As expected, for all galactomannans, the frequency at which $G^{\prime}$ and $G^{\prime \prime}$ become equal to each other moves to lower values as the concentration increases, as a consequence of

Table 2

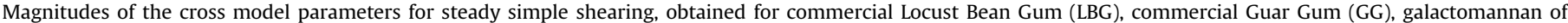
G. triacanthos and galactomannan of S. japonica ( $\pm 95 \%$ confidence interval).

\begin{tabular}{|c|c|c|c|c|c|}
\hline Galactomannan & Concentration/\% & $\eta_{0} /$ Pa.s & $T / \mathrm{s}$ & $m$ & $R^{2}$ \\
\hline \multirow[t]{4}{*}{ LBG } & 1 & $24.74 \pm 0.01$ & $26.44 \pm 5.08$ & $0.505 \pm 0.030$ & 0.96281 \\
\hline & 0.8 & $21.99 \pm 1.01$ & $25.33 \pm 6.08$ & $0.551 \pm 0.014$ & 0.97571 \\
\hline & 0.6 & $5.60 \pm 1.15$ & $16.00 \pm 3.34$ & $0.415 \pm 0.059$ & 0.9723 \\
\hline & 0.4 & $1.46 \pm 0.01$ & $9.91 \pm 0.49$ & $0.320 \pm 0.003$ & 0.98791 \\
\hline \multirow[t]{4}{*}{ GG } & 0.97 & $48.00 \pm 0.08$ & $32.50 \pm 0.17$ & $0.683 \pm 0.003$ & 0.97961 \\
\hline & 0.78 & $26.00 \pm 0.02$ & $22.00 \pm 0.01$ & $0.588 \pm 0.007$ & 0.97871 \\
\hline & 0.58 & $7.30 \pm 0.01$ & $20.00 \pm 0.01$ & $0.551 \pm 0.004$ & 0.99346 \\
\hline & 0.39 & $2.30 \pm 0.03$ & $15.30 \pm 0.01$ & $0.460 \pm 0.007$ & 0.99532 \\
\hline \multirow[t]{4}{*}{ G. triacanthos } & 0.94 & $22.24 \pm 0.03$ & $18.99 \pm 0.18$ & $0.456 \pm 0.004$ & 0.9898 \\
\hline & 0.75 & $20.06 \pm 0.34$ & $13.99 \pm 5.01$ & $0.512 \pm 0.030$ & 0.9823 \\
\hline & 0.56 & $4.74 \pm 0.05$ & $11.99 \pm 4.09$ & $0.548 \pm 0.006$ & 0.9758 \\
\hline & 0.38 & $3.74 \pm 0.01$ & $5.99 \pm 1.00$ & $0.508 \pm 0.016$ & 0.9516 \\
\hline \multirow[t]{4}{*}{ S. japonica } & 0.96 & $30.43 \pm 2.10$ & $26.99 \pm 0.08$ & $0.608 \pm 0.080$ & 0.9899 \\
\hline & 0.77 & $24.74 \pm 0.01$ & $23.02 \pm 0.08$ & $0.588 \pm 0.009$ & 0.9710 \\
\hline & 0.58 & $6.74 \pm 0.45$ & $11.99 \pm 1.21$ & $0.598 \pm 0.005$ & 0.9579 \\
\hline & 0.38 & $2.74 \pm 0.23$ & $11.99 \pm 2.08$ & $0.618 \pm 0.034$ & 0.9878 \\
\hline
\end{tabular}



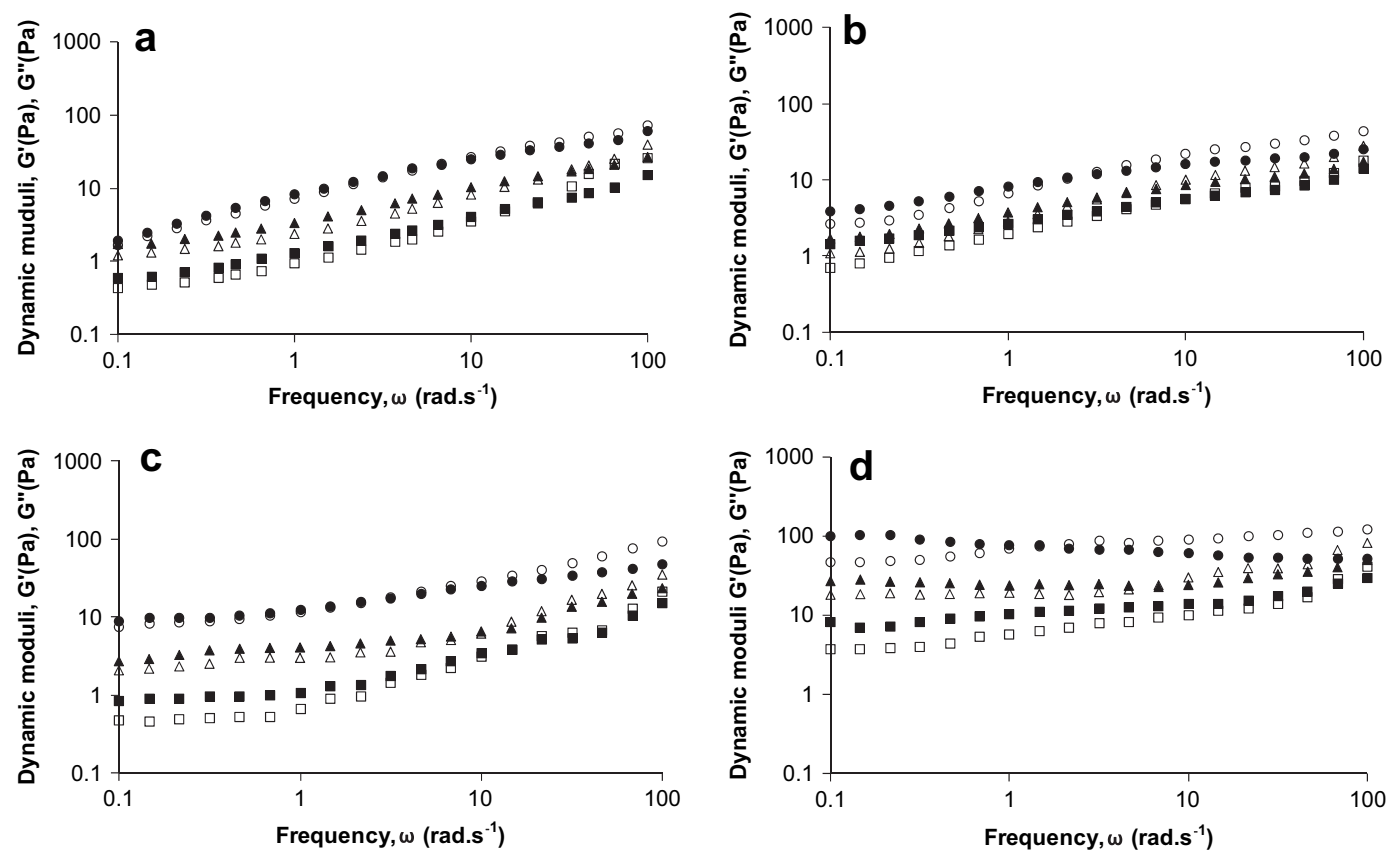

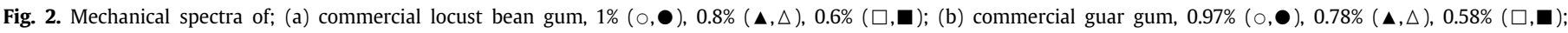

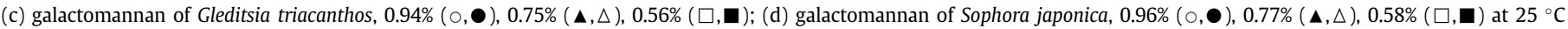
( $G^{\prime}$ : open symbols, $G^{\prime \prime}$ : full symbols).

increasing relaxation times. This feature was found for several other random-coil polysaccharide solutions in the same concentration range (Brummer, Cui, \& Wang, 2003; Sittikijyothin et al., 2005). The $S$. japonica galactomannan solutions exhibit a more pronounced elastic behaviour, with higher values of both $G^{\prime}$ and $G^{\prime \prime}$, compared with the other galactomannan solutions, a reflection of the larger network development in S. japonica solutions, due to its high $\mathrm{M} / \mathrm{G}$ ratio.

\subsection{Extensional properties}

Fig. 3 represents the results of extensional rheology, where the filament diameter $v s$. time profiles for the solutions of the four studied galactomannans (guar gum, locust bean gum, G. triacanthos and $S$. japonica) are shown. All experiments were conducted at $25{ }^{\circ} \mathrm{C}$ using a CaBER rheometer.

From Fig. 3 it can be observed that the polymer filament passes through four stages: the rest phase, the filament stretch phase, the relaxation phase and the breaking of the filament (as illustrated in Fig. 3 a) for $1 \%$ of LBG). The filament evolution is basically controlled by the balance of surface tension and viscous/elastic forces: viscous forces tend to stabilize the filament, while surface tension acts to destabilize it, causing the rapid decrease of the diameter until the filament breaks apart. The shape of the filament diameter vs. time curve and the time of breakup provide information about the extensional rheological properties of fluids. It was found that the increase of biopolymer concentration leads to a delay in filament breakup and that, for the same concentrations, the highest breakup times were obtained for the S. japonica galactomannan, followed by G. triacanthos galactomannan, guar gum, locust bean gum. These results show that the solutions of $S$. japonica galactomannan are more elastic fluids and that LBG solutions, at low concentrations, approach a Newtonian fluid behaviour.

An elastocapillary force balance predicts that the filament radius decays exponentially in time (Rodd, Scott, Cooper-White, and Mckinley (2005)):
$\frac{R_{\text {mid }}(t)}{R_{0}}=\left(\frac{G R_{0}}{2 \sigma_{s}}\right)^{1 / 3} \exp \left[-\frac{t}{3 \lambda_{1}}\right]$

where $R_{\text {mid }}$ is the midpoint radius, $R_{0}$ is the radius at the time zero, $G$ is the elastic module, $\sigma_{\mathrm{S}}$ is the surface tension, $t$ is time and $\lambda_{1}$ is the polymer relaxation time. This relationship has been utilized to determine the relaxation time for many different polymeric solutions over a range of concentrations and molecular weights (Anna \& McKinley, 2001; Bazilevskii, Entov, Lerner, \& Rozhkov, 1997; Bazilevsky, Entov, \& Rozhkov, 1990; Entov \& Hinch, 1997; Liang \& Mackley, 1994; Stelter, Bunn, Yarin, Singh, \& Durst, 2000).

Eq. (3) was initially used to predict the behaviour of solution galactomannans for all the studied concentrations and temperatures; however, a poor fit of this equation to the experimental data was observed for the highest concentrations and for the lowest temperatures, as shown in Fig. 4 a) for $1 \%$ locust bean gum at $25^{\circ} \mathrm{C}$ (concentration, gum and temperature taken as example), revealing the involvement of another physical mechanism. To include this mechanism and consequently, obtain a better fit to experimental data, Eq. (3) was modified and the existence of a second relaxation time $\left(\lambda_{2}\right)$ was considered:

$\frac{R_{\mathrm{mid}}(t)}{R_{0}}=\left(\frac{G R_{0}}{2 \sigma_{s}}\right)^{1 / 3} \exp \left[-\frac{t}{3 \lambda_{1}}\right]+\left(\frac{G R_{0}}{2 \sigma_{s}}\right)^{1 / 3} \exp \left[-\frac{t}{3 \lambda_{2}}\right]$

Fig. $4 \mathrm{~b}$ ) clearly shows the improvement of the fitting provided by the addition of a second term to Eq. (3). For concentrations lower than 0.4 the fit obtained by using of Eq. (3) or Eq. (4) is similar (see Fig. 4c) and d)). Table 3 show the physical parameters obtained at different concentrations in the relaxation phase, at $25^{\circ} \mathrm{C}$, calculated based on Eq. (4). It can be observed that both the elastic modulus and the relaxation times decrease with decreasing polymer concentration. The highest values of these parameters were obtained for the $S$. japonica galactomannan which reflect the development of a larger network structure due to the presence of expanded molecules that allow the establishment of numerous associations polymer-polymer, as mentioned before. 

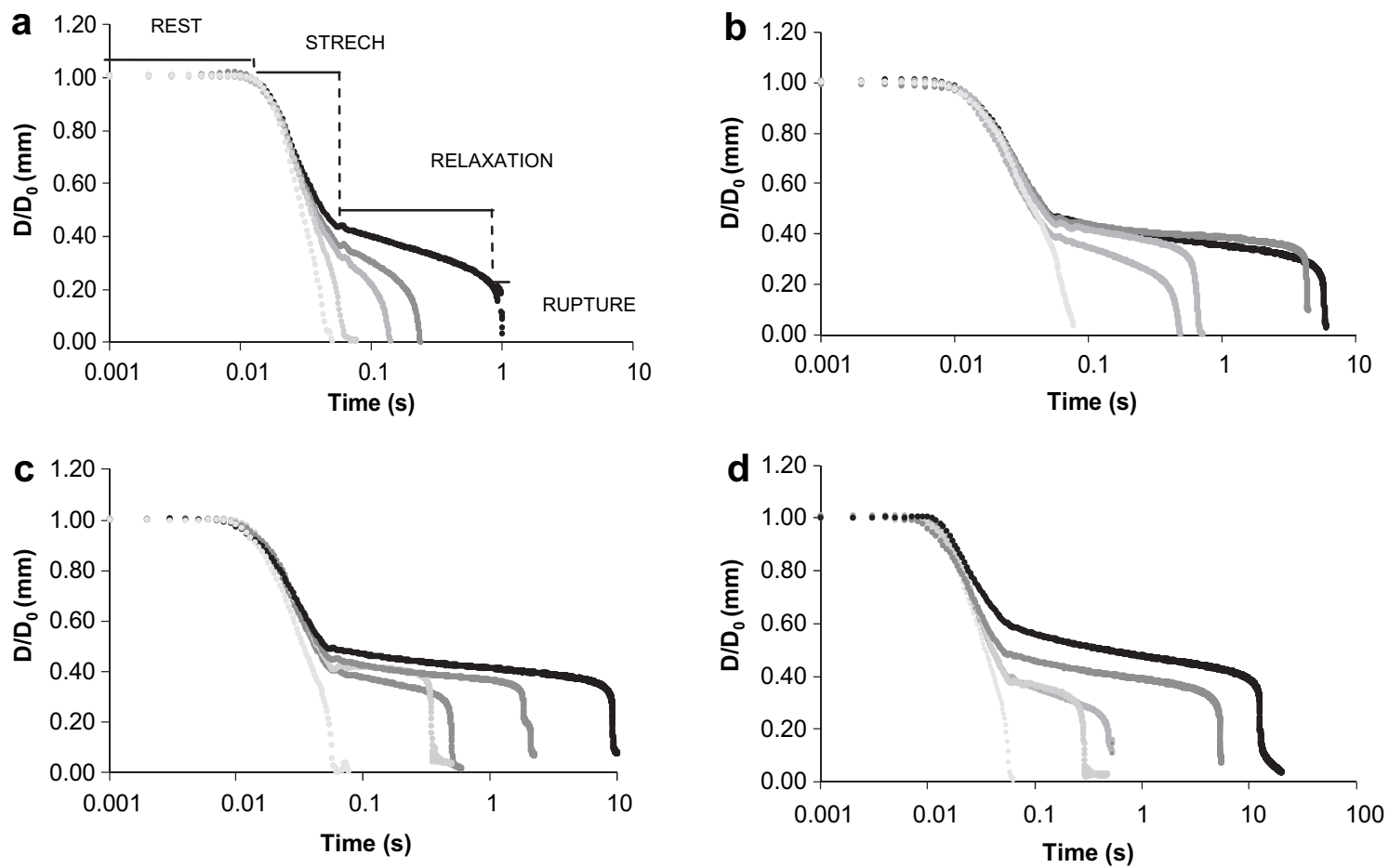

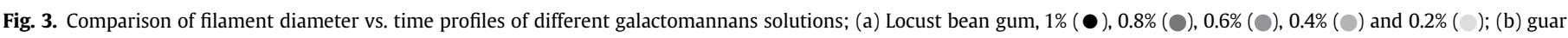

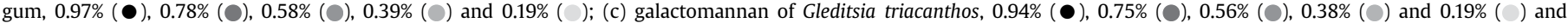
$(\mathrm{d})$ galactomannan of Sophora japonica, $0.96 \%(\bullet), 0.77 \%(\bigcirc), 0.58 \%(\bigcirc), 0.38 \%(\bigcirc)$ and $0.19 \%(\bigcirc)$. All experiments were conducted at $25{ }^{\circ} \mathrm{C}$ using a CaBER rheometer.
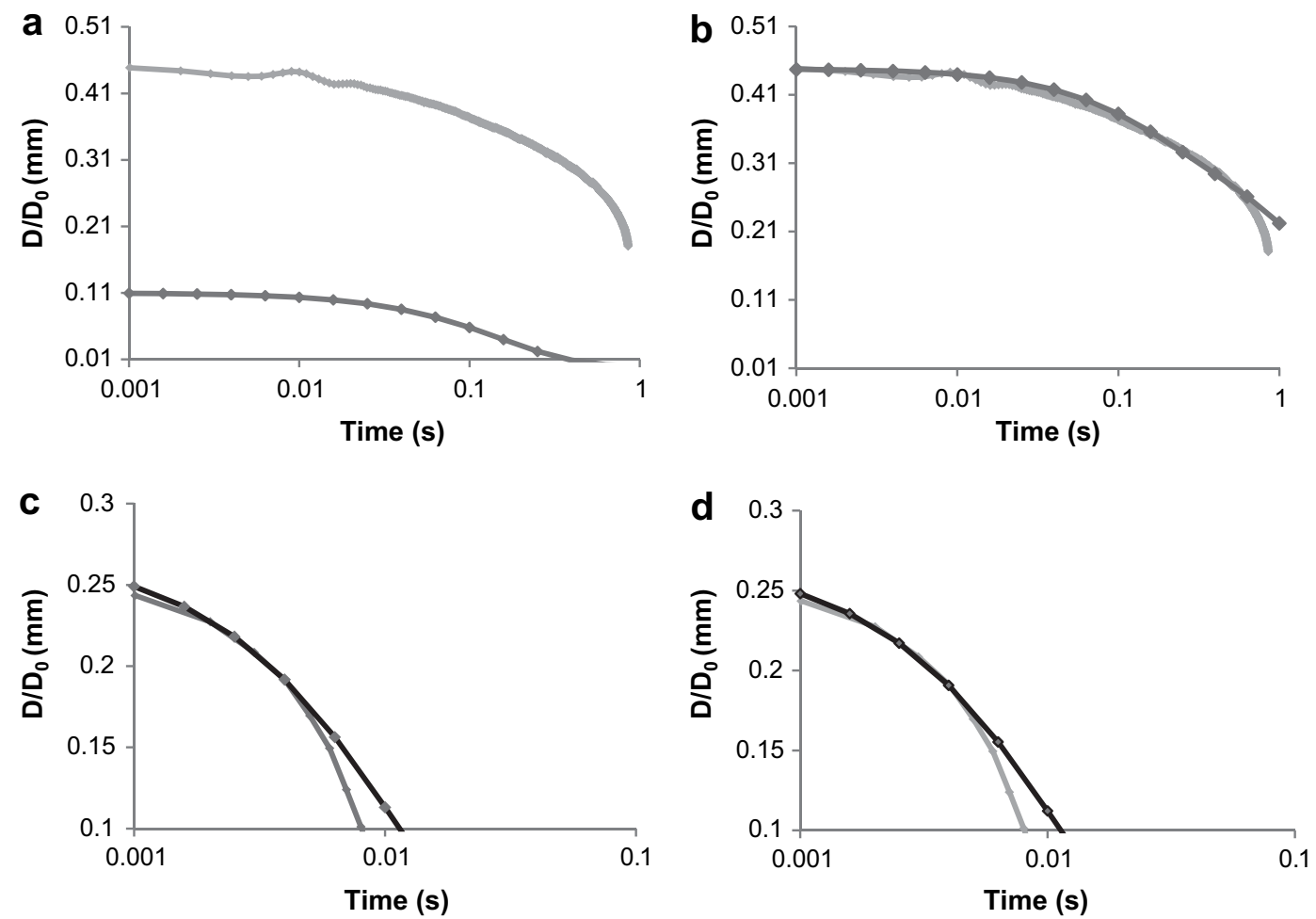

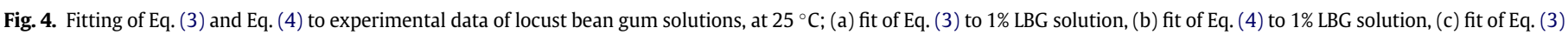
to $0.4 \%$ LBG solution, (d) fit of Eq. (4) to $0.4 \%$ LBG solution (experimental data: , best fit of the Eq. (3) or Eq. (4) to the experimental data: $\bullet$ ). 
Table 3

Physical parameters of galactomannans solutions, at $25^{\circ} \mathrm{C}$, in extensional rheology ( $\pm 95 \%$ confidence interval).

\begin{tabular}{lllll}
\hline Galactomannan & Concentration/\% & G/Pa & $\lambda_{1} / \mathrm{s}$ & $\lambda_{2} / \mathrm{s}$ \\
\hline LBG & 1 & $4.07 \pm 0.01$ & $0.054 \pm 0.006$ & $0.780 \pm 0.010$ \\
& 0.8 & $2.97 \pm 0.01$ & $0.030 \pm 0.003$ & $0.350 \pm 0.010$ \\
& 0.6 & $2.22 \pm 0.01$ & $0.015 \pm 0.006$ & $0.070 \pm 0.020$ \\
& 0.4 & $1.28 \pm 0.02$ & $0.004 \pm 0.003$ & $0.002 \pm 0.001$ \\
GG & 0.2 & $0.97 \pm 0.01$ & $0.003 \pm 0.001$ & $0.001 \pm 0.001$ \\
& 0.97 & $4.14 \pm 0.06$ & $0.058 \pm 0.009$ & $4.200 \pm 0.050$ \\
& 0.78 & $3.38 \pm 0.01$ & $0.047 \pm 0.002$ & $2.200 \pm 0.010$ \\
& 0.58 & $3.31 \pm 0.03$ & $0.043 \pm 0.002$ & $0.090 \pm 0.010$ \\
G. triacanthos & 0.39 & $2.02 \pm 0.02$ & $0.025 \pm 0.007$ & $0.003 \pm 0.001$ \\
& 0.19 & $1.20 \pm 0.01$ & $0.015 \pm 0.009$ & $0.001 \pm 0.001$ \\
& 0.94 & $5.73 \pm 0.13$ & $0.059 \pm 0.002$ & $5.200 \pm 0.080$ \\
& 0.75 & $3.72 \pm 0.05$ & $0.049 \pm 0.001$ & $3.170 \pm 0.090$ \\
& 0.56 & $2.78 \pm 0.13$ & $0.026 \pm 0.001$ & $0.270 \pm 0.020$ \\
S. japonica & 0.38 & $2.26 \pm 0.09$ & $0.009 \pm 0.001$ & $0.008 \pm 0.001$ \\
& 0.19 & $1.23 \pm 0.09$ & $0.006 \pm 0.002$ & $0.002 \pm 0.002$ \\
& 0.96 & $8.07 \pm 0.23$ & $0.077 \pm 0.006$ & $12.000 \pm 0.05$ \\
& 0.77 & $4.71 \pm 0.09$ & $0.057 \pm 0.004$ & $4.170 \pm 0.010$ \\
& 0.58 & $3.52 \pm 0.11$ & $0.058 \pm 0.004$ & $0.420 \pm 0.010$ \\
& 0.38 & $2.00 \pm 0.04$ & $0.009 \pm 0.003$ & $0.004 \pm 0.001$ \\
& 0.19 & $1.98 \pm 0.04$ & $0.008 \pm 0.002$ & $0.002 \pm 0.001$ \\
\hline
\end{tabular}

The existence of two relaxation times may be due to the structure of the studied polysaccharides, since besides the expansion of the polymeric chains, the existence of the interactions between the chains delays the relaxation phase. In this case $\lambda_{1}$ represents a time scale associated with elongation or stretching of polymer molecules (unravelling the polysaccharide chains) (Duxenneuner, Fisher, Windhab, \& Cooper-White, 2008) and $\lambda_{2}$ possibly refers to the destruction of the links between the chains. As the concentration decreases, $\lambda_{2}$ becomes more and more insignificant as a consequence of a greater freedom of movements of individual chains.

Fig. 5 shows the effect of temperature on the variation of filament diameter with time for the $1 \%$ solutions of the four

\section{Table 4}

Physical parameters of galactomannans solutions, at different temperatures $( \pm 95 \%$ confidence interval).

\begin{tabular}{llllr}
\hline Galactomannan & $\begin{array}{l}\text { Temperature } \\
\left({ }^{\circ} \mathrm{C}\right)\end{array}$ & \multicolumn{1}{l}{$\mathrm{Pa})$} & \multicolumn{1}{l}{$\lambda_{1}(\mathrm{~s})$} & $\lambda_{2}(\mathrm{~s})$ \\
\hline $1 \%$ LBG & 25 & $4.07 \pm 0.01$ & $0.054 \pm 0.002$ & $0.78 \pm 0.01$ \\
& 40 & $2.97 \pm 0.07$ & $0.012 \pm 0.009$ & $0.46 \pm 0.02$ \\
& 50 & $2.22 \pm 0.07$ & $0.010 \pm 0.004$ & $0.31 \pm 0.01$ \\
& 60 & $1.25 \pm 0.09$ & $0.004 \pm 0.006$ & $0.08 \pm 0.01$ \\
& 80 & $0.97 \pm 0.01$ & $0.003 \pm 0.007$ & $0.06 \pm 0.02$ \\
$0.97 \%$ GG & 25 & $4.14 \pm 0.06$ & $0.058 \pm 0.007$ & $4.20 \pm 0.05$ \\
& 40 & $3.38 \pm 0.12$ & $0.035 \pm 0.006$ & $4.00 \pm 0.11$ \\
& 50 & $3.31 \pm 0.02$ & $0.018 \pm 0.003$ & $3.50 \pm 0.10$ \\
& 60 & $1.99 \pm 0.01$ & $0.010 \pm 0.002$ & $1.40 \pm 0.10$ \\
$0.94 \%$ & 80 & $1.22 \pm 0.01$ & $0.008 \pm 0.002$ & $0.90 \pm 0.08$ \\
G. triacanthos & 40 & $5.73 \pm 0.13$ & $0.059 \pm 0.002$ & $5.20 \pm 0.08$ \\
& 50 & $3.24 \pm 0.01$ & $0.036 \pm 0.004$ & $4.17 \pm 0.05$ \\
& 60 & $2.59 \pm 0.02$ & $0.030 \pm 0.008$ & $3.99 \pm 0.03$ \\
& 80 & $2.38 \pm 0.11$ & $0.018 \pm 0.006$ & $2.40 \pm 0.02$ \\
$0.96 \%$ S. japonica & 25 & $1.32 \pm 0.01$ & $0.017 \pm 0.004$ & $2.00 \pm 0.01$ \\
& 40 & $8.07 \pm 0.23$ & $0.077 \pm 0.006$ & $12.00 \pm 0.05$ \\
& 50 & $5.43 \pm 0.02$ & $0.045 \pm 0.013$ & $7.00 \pm 0.04$ \\
& 60 & $3.20 \pm 0.05$ & $0.040 \pm 0.010$ & $4.50 \pm 0.05$ \\
& 80 & $2.41 \pm 0.10$ & $0.015 \pm 0.004$ & $2.92 \pm 0.11$ \\
& & $1.82 \pm 0.23$ & $0.010 \pm 0.008$ & $2.80 \pm 0.16$ \\
\hline
\end{tabular}

galactomannans. It can be seen that in all cases, as the temperature raises from $25{ }^{\circ} \mathrm{C}$ to $80{ }^{\circ} \mathrm{C}$ the breakup time decreases and the solutions' behaviour comes close to Newtonian fluid behaviour.

Table 4 show the physical parameters obtained at different temperatures in the relaxation phase for galactomannan solutions with similar concentrations and it can be observed that both the relaxation time and the elastic modulus decrease as temperature increases. With the increase of temperature there is a more effective destruction of the links between the chains (rupture of $\mathrm{H}$-bonds involved in the interchain interactions) and, consequently, the mobility of the chains increases. It can also be observed that the
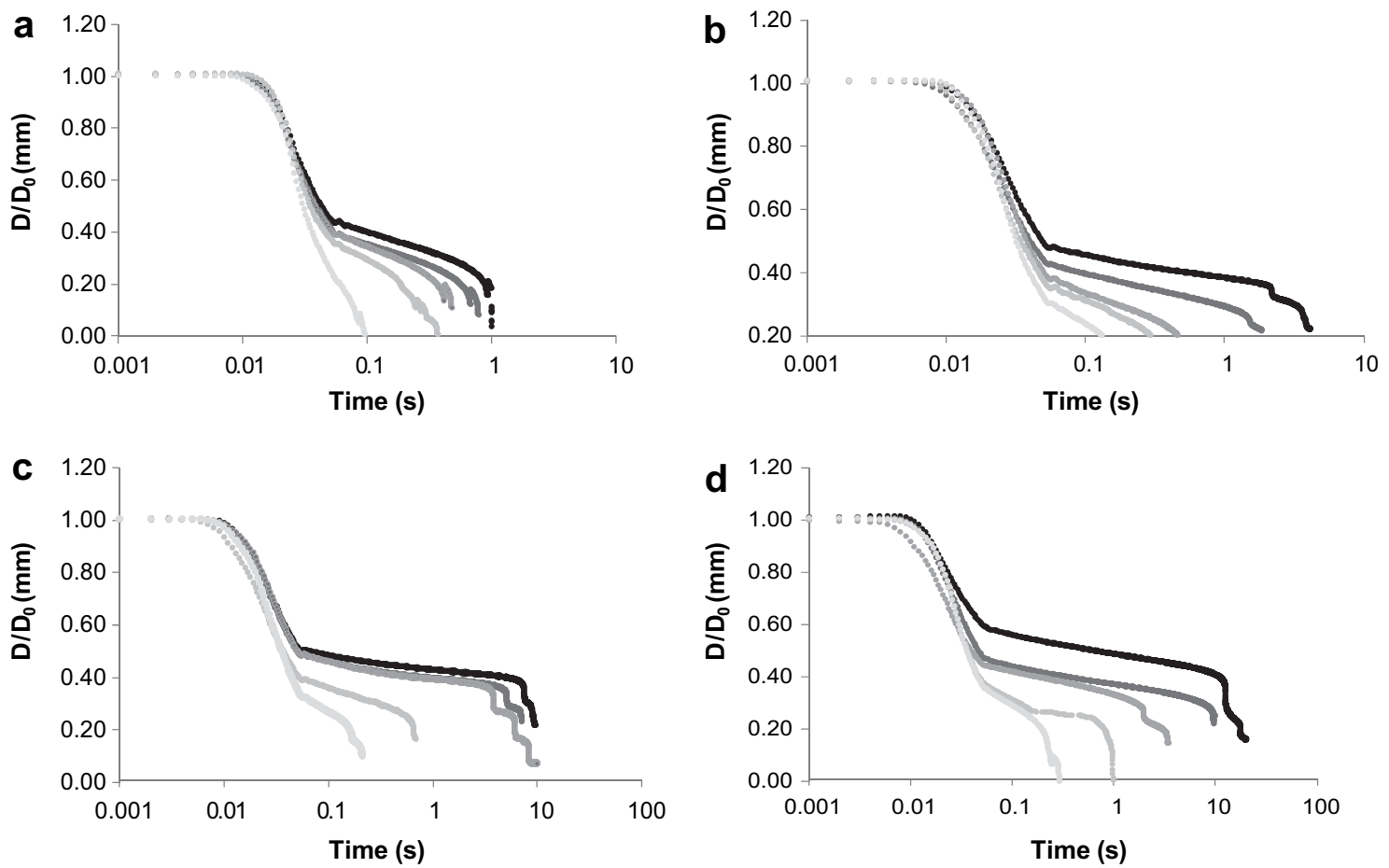

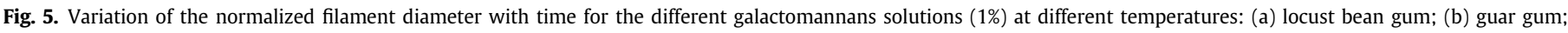
(c) galactomannan of Gleditsia triacanthos and (d) galactomannan of Sophora japonica, $25^{\circ} \mathrm{C}(\bullet), 40{ }^{\circ} \mathrm{C}(\bigcirc), 50{ }^{\circ} \mathrm{C}(\bigcirc), 60{ }^{\circ} \mathrm{C}(\bigcirc), 80{ }^{\circ} \mathrm{C}(\bigcirc)$. 
S. japonica galactomannan exhibits the highest values of these parameters at all studied temperatures, followed by G. triacanthos, guar gum and locust bean gum. This indicates that the interchain interactions established by S. japonica and G. triacanthos galactomannan chains among them are more resistant to temperature when compared to the ones established by the guar gum and locust bean gum.

The values for the breakup times of the polymer solutions' filaments are not shown, because it was observed that the measurements in CaBER rheometer were not satisfactorily reproducible. For the same solution, the relaxation patterns obtained were similar, however the absolute values of filament breakup times were significantly different (error percentage in the range of $70 \%$ ).

\section{Conclusions}

The obtained results showed that all the studied galactomannans exhibited a shear-thinning behaviour in the range of concentration and shear rates studied. Experimental data obtained under steady shear were correlated with the Cross model and this model described well the viscosity shear rate data of all galactomannan solutions. The dynamic shear experiments showed that the galactomannan of $S$. japonica leads to more elastic solutions compared with the other studied galactomannans, which could be an attractive for the use of this gum in some food applications.

The extensional rheology showed that the breakup time, relaxation time and elastic modulus decreased with decreasing polymer concentration and with increase temperature. The higher values of these parameters were obtained for S. japonica galactomannan and are in agreement with shear rheology results.

The obtained results indicate that the galactomannans of G. triacanthos and S. japonica may offer an excellent alternative for guar and locust bean gums as thickening agents.

\section{Acknowledgments}

The author C. Ribeiro was recipient of a fellowship from the Fundação para a Ciência e Tecnologia (FCT, Portugal). The authors would like to acknowledge to Dr. Mafalda Quintas for helping in modelling and to Dr. Maria do Carmo Avides for her support with protein determination.

\section{References}

Andrade, C. T., Azero, E. G., Luciano, L., \& Gonçalves, M. P. (1999). Solution properties of the galactomannans extracted from the seeds of Caesalpinia pulcherrima and Cassia javanica: comparison with locust bean gum. International Journal of Biological Macromolecules, 26, 181-185.

Andrade, C. T., Azero, E. G., Luciano, L., \& Gonçalves, M. P. (2000). Rheological properties of mixtures of k-carrageenan from Hypnea musciformis and galactomannan from Cassia javanica. International Journal of Biological Macromolecules, 27, 349-353.

Anna, S. L., \& McKinley, G. H. (2001). Elasto-capillary thinning and breakup of mode elastic liquids. Jounal of Rheology, 45(1), 115-138.

AOAC Standards. (1975). 12th ed., section 31-012, Washington DC, USA.

Azero, E. G., \& Andrade, C. T. (2006). Characterization of Prosopis juliflora seed gum and the effect of its addition to K-Carrageenan systems. Journal of Brazilian Chemical Society, 17(5), 844-850.

Bazilevskii, A. V., Entov, V. M., Lerner, M. M., \& Rozhkov, A. N. (1997). Failure of polymer solution filaments, 39(3), 316-324.

Bazilevsky, A. V., Entov, V. M., \& Rozhkov, A. N. (1990). Liquid filament microrheometer and some of its applications. In D. R. Oliver (Ed.), Third European rheology conference (pp. 41-43). Elsevier Applied Science.

Blair, R. M. (1990). Gleditsia triacanthos L, honeylocust. In R. M. Burns, \& B. H. Honkala (Eds.), Silvics of North American Trees, Vol. 2 (pp. 358-364). Washington, DC: USDA Forest Service.
Bradford, M. M. (1976). A rapid and sensitive method for the quantitation of microgram quantities of protein utilizing the principle of protein-dye binding. Analytical Biochemistry, 72, 248-254.

Bresolin, T. M. B., Milas, M., Rinaudo, M., Reicher, F., \& Ganter, J. L. M. S. (1999). Role of galactomannan composition on the binary gel formation with xanthan. International Journal of Biological Macromolecules, 26, 225-231.

Brummer, Y., Cui, W., \& Wang, Q. (2003). Extraction, purification and physicochemical characterization of fenugreek gum. Food Hydrocolloids, 17, 229-236.

Casas, J. A., Mohedano, A. F., \& Garcia-Ochoa, F. (2000). Viscosity of guar gum and xanthan/guar gum mixture solutions. Journal of the Science of Food and Agriculture, $80,1722-1727$.

Cerqueira, M. A., Pinheiro, A. C., Souza, B. W. S., Lima, A. M. P., Ribeiro, C., Miranda, C., et al. (2009). Extraction, purification and characterization of galactomannans from non-traditional sources. Carbohydrate Polymers, 75, 408-414.

Chan, P. S.-K., Chen, J., Ettelaie, R., Law, Z., Alevisopoulos, S., Day, E., et al. (2007). Study of the shear and extensional rheology of casein, waxy maize starch and their mixtures. Food Hydrocolloids, 21, 716-725.

Cheng, Y., Brown, K. M., \& Prud'homme, R. K. (2002). Preparation and characterization of molecular weight fractions of guar galactomannans using acid and enzymatic hydrolysis. International Journal of Biological Macromolecules, 31(1-3), 29-35.

Choi, H. M., \& Yoo, B. (2008). Rheology of mixed systems of sweet potato starch and galactomannans. Starch, 60, 263-269.

Cross, M. M. (1965). Rheology of non Newtonian fluids: a new flow equation for pseudoelastic systems. Journal of Colloid Science, 20, 417-437.

Dakia, P. A., Blecker, C., Roberta, C., Watheleta, B., \& Paquota, M. (2008). Composition and physicochemical properties of locust bean gum extracted from whole seeds by acid or water dehulling pre-treatment. Food Hydrocolloids, 22, 807-818.

Dea, I. C. M., Clark, A. H., \& McCleary, B. V. (1986). Effect of molecular fine structure of galactomannans on their interaction properties. The role of unsubstituted sides. Food Hydrocolloids, 1, 129-140.

Dea, I. C. M., \& Morrison, A. (1975). Chemistry and interactions of seed galactomannans. Advances in Carbohydrate Chemistry and Bio-Chemistry, 31, 241-242.

Doublier, J. L., \& Launay, B. (1981). Rheology of galactomannan solutions: comparative study of guar gum and locust bean gum. Journal of Texture Studies, 12, $151-172$.

Duxenneuner, M. R., Fisher, P., Windhab, E. J., \& Cooper-White, J. J. (2008). Extensional properties of hydroxypropyl ether guar gum solutions. Biomacromolecules, 9, 2989-2996.

Egorov, A. V., Mestechkina, N. M., \& Shcherbukhin, V. D. (2003). Determination of the primary and fine structures of a galactomannan from the seed of Gleditsia triacanthos f. inermis L. Applied Biochemistry and Microbiology, 39, 398-402.

Egorov, A. V., Mestechkina, N. M., \& Shcherbukhin, V. D. (2004). Composition and structure of galactomannan from the seed of Gleditsia ferox Desf. Applied Biochemistry and Microbiology, 40, 314-318.

Entov, \& Hinch. (1997). Effect of a spectrum of relaxation times on the capillary thinning of a filament of elastic liquid. Journal Non-Newtonian Fluid Mechanics, $72,31-53$.

Fernandes, P. B., Gonçalves, M. P., \& Doublier, J. L. (1991). A rheological characterization of Kappa-carrageenan/galactomannan mixed gels: a comparison of locust bean gum samples. Carbohydrate Polymers, 16, 253-274.

Garti, N., Madar, Z., Aserin, A., \& Sternheim, B. (1997). Fenugreek galactomannans as food emulsifiers. Food Science and Technology, 30(3), 305-311.

Hernandez, M. J., Dolz, J., Dolz, M., Delegido, J., \& Pellicer, J. (2001). Viscous sinergism in carrageenan ( $k$ and $\lambda$ ) and locust bean gum mixtures: influence of adding sodium carboxymethylcellulose. Food Science and Technology International, 7, 383-391.

Ishida, H., Umino, T., Tsuji, K., \& Kosuge, T. (1989). Studies on the antihemorrhagic substances in herbs classified as hemostatics in Chinese medicine X. On hemostatic activities of the parched herbs for hemostatics. Yakugaku Zasshi, 109, 179-183.

Liang, R. F., \& Mackley, M. R. (1994). Rheological characterization of the time and strain Dependence for Polyisobutylene solutions. Journal of Non-Newtonian Fluid Mechanics, 52, 387-405.

Manzi, A. E., Mazzini, M. N., \& Cerezo, A. S. (1984). The galactomannan system from the endosperm of the seed of Gleditsia triacanthos. Carbohydrate Research, 125, 127-143.

Marcotte, M., Taherian, A. R., Trigui, M., \& Ramaswamy, H. S. (2001). Evaluation of rheological properties of selected salt enriched food hydrocolloids. Journal of Food Engineering, 48, 157-167.

Mazzini, M. N., \& Cerezo, A. S. (1979). The carbohydrate and protein composition of the endosperm, embryo and testa of the seed of Gleditsia triacanthos. Journal of Science Food Agriculture, 30(9), 881-891.

Morris, E. R., \& Taylor, L. J. (1982). Oral perception of fluid viscosity. Progress in Food and Nutrition Science, 6, 285-296.

Odell, J. A., \& Carrington, S. P. (2006). Extensional flow oscillatory rheometry. Journal of Non-Newtonian Fluid Mechanics, 137, 110-112.

Padmanabham, M. (2003). Extensional rheology. In D. R. Heldman, Enclycopedia of agricultural, food and biological engineering, 282-289.

Parvathy, K. S., Nuggehalli, S. S., \& Tharanathana, R. N. (2007). Hydration characteristics of guar gum samples and their fractions. Food Hydrocolloids, 21, 630-637.

Patel, S. P., Ranjan, G., \& Patel, V. S. (1987). Rheological properties of guar gum and hydroxyethyl guar gum in aqueous solution. International Journal of Biological Macromolecules, 9(6), 314-320.

Ranganna, S. (1977). Handbook of analysis of quality control for fruits and vegetable products (2nd ed.). New Delhi: Tata McGraw-Hill Publishing Co. Ltd. 
Rodd, L. E., Scott, T. P., Cooper-White, J. J., \& Mckinley, G. H. (2005). Capillary breakup rheometry of low-viscosity elastic fluids. Applied Rheology, 15, 12-27.

Schorsch, C., Gamier, C., \& Doublier, J. (1997). Viscoelastic properties of xanthan/ galactomannan mixtures: comparison of guar gum with locust bean gum. Carbohydrate Polymers, 34, 165-175.

da Silva, J. A. L., Gonçalves, M. P., \& Rao, M. A. (1992). Rheological properties of highmethoxyl pectin and locust bean gum solutions in steady shear. Journal of Food Science, 57, 443-448.

Sittikijyothin, W., Torres, D., \& Gonçalves, M. P. (2005). Modelling the reological behaviour of galactomannan aqueous solutions. Carbohydrate Polymers, 59, 339-350.

Steffe, J. F. (1996). Rheological methods in food process engineering. Michigan (2nd ed.). Freeman Press. pp.255.
Stelter, M., Brenn, G., Yarin, A. L., Singh, R. P., \& Durst, F. (2000). Validation and application of a novel elongational device for polymer solutions. Journal of Rheology, 44(3), 595-616.

Sujatha, K. S., Matallah, H., Banaai, M. J., \& Webster, M. F. (2008). Modelling step-strain filament-streching (CaBER-type) using ALE techniques. Journal of Non-Newtonian Fluid Mechanics, 148, 109-121.

Tang, Y. P., Lou, F. C., Wang, J. H., \& Zhuang, S. F. (2001). Four new isoflavone triglycosides from Sophora japonica. Journal of Natural Products, 64, 1107-1110.

Üner, M., \& Altınkurt, T. (2004). Evaluation of honey locust (Gleditsia triacanthos Linn.) gum as sustaining material in tablet dosage forms. IL FARMACO, 59, 567-573.

Wientjes, R. H. W., Duits, M. H. G., Jongschaap, R. J. J., \& Mellema, J. (2000). Linear rheology of guar gum solutions. Macromolecules, 33(26), 9594-9605. 